\title{
ANTHROPOGENIC FIRE REGIME DETECTION USING 1953 AERIAL PHOTOGRAPH REPOSITORY FROM THE WESTERN DESERT OF AUSTRALIA
}

\author{
Fabian Surya Pramudya ${ }^{1}$, Michael Holton Price ${ }^{2}$, Agung Budi Harto ${ }^{1}$, \\ Ketut Wikantika ${ }^{1}$, Rebecca Bliege Bird ${ }^{2}$ \\ ${ }^{1}$ Geodesy and Geomatics Engineering Program, Institute of Technology, Bandung (ITB) \\ ${ }^{2}$ Department of Anthropology, Pennsylvania State University (PSU)
}

Keywords : Aboriginal burning, CLAHE, GLCM, OBIA, Object Based Segmentation

\begin{abstract}
Covered by arid and semi-arid desert, 70 percent of Australia mainland has known for years for it's social and cultural phenomenon of Aborigin people, the indigenous Australian tribes. Several comunities of Aboriginal tribes, such as Martu people, has developed methods according to genders, to meet their daily needs of food during the cool-dry season from May to August. Men focus on gun hunting, while the women focus on hunting wooden or iron digging sticks and burning small fires on a regular basis to support their foraging activities. Many researchers suggested that moderate and repeated burning has several positive impacts to the surrounding biotic web and terrestrial biodiversity, while preventing habitat loss at the local scale. Remote Sensing method, such as aerial photography and satellite imagery, are suitable technology that developed to acquire certain data or information in large-scale measurement especially in quantify past and present fire activity at spatial scales useful for a range of fire and vegetation management applications. In this research, an ununiformed illumination of Australian Panchromatic 1953 aerial image repository were reconstructed to widen the known information obtained using Landsat satellite mission data sets from 1970's. The geometric reconstruction of the imagery was done using GCP acquired from Panchromatic Landsat 8 data using still land objects. The radiometric reconstruction was done using Contrast Limited Adaptive Histogram Equalization method, to the non-uniform illumination on each flight path, and stitched into mosaic. The objective of this research is to evaluate the effectiveness of methods in Object Based Image Analysis (OBIA) feature extraction by using GLCM in very limited spectral information by comparing advance segmentation technique, the Multiresolution Segmentation and Segmentation.
\end{abstract}

\section{INTRODUCTION}

Arid and semi-arid desert lands covers 70 percent of mainland Australia (Davies, 2009). In a total of about 5.3 million square kilometres, these areas are divided into ten major Australian deserts. A large proportion of this land is held by Aboriginal people through various property titles (Wells, 2013). In Western Australia, Martu people, whose country includes the communities north of Wiluna, of Jigalong, Parngurr and Punmu, is the indigenous owners of around 150,000 square kilometers of desert. This contemporary Aboriginal communities has developed methods according to genders, to meet their daily needs of food during Wantajarra (cool-dry season from May to August). Men focus on gun hunting for mobile game, while the women focus on hunting for smaller burrowed animals using wooden or iron digging sticks and burning small fires on a regular basis to support their foraging activities (Wells, 2013, Bird, 2005, Bird, 2008).

Further investigation into the relationship between habitat mosaic, burning patterns, and foraging efficiency will require large-scale measures of habitat mosaic and burning regimes with remote sensing and GIS technologies and associated variability in the efficiency of foraging for all types of resources (Bird, 2005). Remote Sensing method, such as aerial photography and satellite imagery, are suitable technology that developed to acquire certain data or information in large-scale measurement especially in quantify past and present fire activity at spatial scales useful for a range of fire and vegetation management applications.

Time series observation require a wide range of data. Integration between the old aerial photographs repository and LANDSAT satellite imagery, which was launched in 1972 and has a temporal resolution of 14-16 days, were able to meet the need of a sustainable quantification of fire regimes information. The use of old aerial photograps taken in different times and conditions in this study raises new challenges in both pre-processing and identification of burning regime radiometrically and geometrically. Several researchers has proposed algorithms that could be applied to solve this problem, such as Redweik, et al. (2009) and Min, et al. (2013) in radiometric method of recovering old aerial protographs, Huang (2014) in classification method based on Haralick, et al. (1973) multichannel image gray level co-occurrence matrix (GLCM) textural approach, and Kressler, et al. (2005) in object based image analysis for segementation and classification of aerial images. The results of the quantification of anthropogenic fire using this can be used to identify patterns and the amount of area burned in 1953. Later, the results of this study could became a basis of future burning regime prediction and broaden the paradigm in understanding the Aboriginal communities foraging activities in Australia's western desert. 


\section{RESEARCH OBJECTIVES}

The availability of historic aerial images from 1953 and more recent Landsat 7 and Landsat 8 imagery allow broader analysis and discussion about anthropogenic fire regimes. However, the use of old aerial photographs repository raises some issues. For example, can burning regimes be identified using very limited spectral information in old aerial photographs? Is it possible to differentiate between natural and anthropogenic fire regime using spectral-textural classification parameters? Is it also possible to integrate historical aerial images with Landsat images to accomplish a meaningful diachronic analysis of burning regimes?

This study addresses these issues, and hopes to expand on previous work in the field by proposing an algorithm to identify and quantify anthropogenic fire regime using a historic 1953 aerial photograph repository by comparing two advance segmentation methods in Object Based Image Analysis (OBIA); the Contrast Filter Segmentation and Multiresolution Segmentation. Further analysis using the results will be conducted as a complimentary step of this research.

\section{AREA OF INTEREST AND DATA}

The geographic focus of this research is a section of the western Australian desert bounded by the latitude/longitude points $22^{\circ} 00^{\prime} 51^{\prime \prime} \mathrm{S}, 127^{\circ} 06^{\prime} 02^{\prime \prime} \mathrm{E}$ and $23^{\circ} 19^{\prime} 55^{\prime \prime} \mathrm{S}, 128^{\circ} 17^{\prime} 14^{\prime \prime}$ E. Lake Mackay is located in the north-east portion of this area, as depicted by the red square in Figure 1.1.

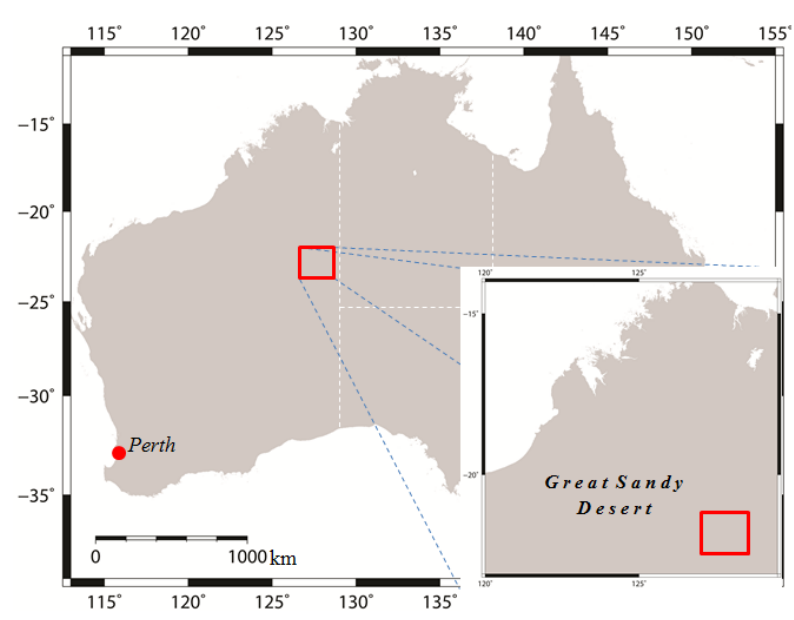

Figure 1. Area of Interest (GAMIT/ GLOBK, 2014)

The primary data used in this study were Landsat 8 scenes; historical aerial images repository of Australia. This region is covered by four Landsat 8 scenes, with the paths and rows: 105/75, 105/76, 106/075, and 106/076. Another remote sensing dataset used in this research is an aerial photograph repository which was collected between June 27th, 1953, and July 27th, 1953 using a K-17 metric camera. LANDSAT 8 satellite imagery recorded on the date of July 27,2014 on path number 106-107 and row number 75-76. In addition to primary data, secondary data used is shapefiles of sample and ground truth data of burning regime, sampled by researchers from Department of Anthropology, Pennsylvania State University

\section{GEOMETRIC CORRECTION}

Data used in this research is 1953 aerial image taken by the British Airforce. Unfortunately, only altitude and focal length information are known for the dataset. Additional camera parameters are also not known, aside the use of K17 metric camera. There are also no Ground Control Points (GCPs) information could be retrieved from the data sets. The dataset consists of 301 photographs, with less than $30 \%$ overlap between images due to the missing images in the dataset, while the requirement of endlaps and sidelaps are $60 \%$ and $30 \%$ for standard aerial photograph data acquisition (Brinker and Minnic, 1995).

Unable to perform the photogrammetric process to the data due to the insufficient percentage of end lap and the unavailability of GCPs, the sets of aerial images is assumed as single channel panchromatic satellite images data. In satellite image data pre-processing, influences such as sensor configuration, change in position and height sensor 
(scalling factor), vehicle speed, and sensor recording angle, can cause geometric distortion (Campbell, 1987; Lillesand and Kiefer, 1994; Jensen, 1996).

In order of correct the size, position, and shape of the object on the earth's surface on a satellite image to the real situation on the map, it is necessary to eliminate the geometric correction of the geometric distortions. In this research Geometric correction performed using the Ground Control Point (GCP) as the common point for calculating the coordinate transformation parameter in projective coordinate system, due to the available orthorectified imagery of Landsat 8, Published by The United States Geological Surveys (USGS, in http://earthexplorer.usgs.gov) in Universal Transverse Mercator (UTM) projective coordinate system. Image to map registration is done by calculating minimum of 15 GCPs with UTM projective coordinates in zone 50 south using WGS 1984 datum. Coordinate transformation parameter used in this step is second order polynomial equation. A polynomial transformation is a non-linear transformation and relates two 2D Cartesian coordinate systems through a translation, a rotation and a variable scale change (Knipper, 2001; de By, 2001).

To obtain the best result, GCP point chosen should be spread evenly to accommodate differences in the position of the entire image so that the geometric correction can be more evenly distributed. in this study, the chosen object for GCPs are sand dunes, assuming as the still objects of the aerial image to the 15 meter Landsat panchromatic image reference. The identification of Aircraft position of image exposure is known from the original Webb W.A Zone 3.4 Flight Plan. Using this technique, the result of image transformation also shown the attitude of the aircraft movement and the sensor recording angle. Accuracy geometric correction process is tested by determining the 10 other points as ICP at the same point on the aerial image and referenced image. ICP have been scattered in the major rivers that exist at the center of the island and is different from the point of GCP. The quality of the points selected GCP and ICP can be seen through the value of the root mean square error (RMSE) through the following algorithm (Moses, 2012):

$$
R M S E=\sqrt{\frac{\sum \Delta x^{2}+\sum \Delta y^{2}}{n}}
$$

where $\Delta \mathrm{x}$ is the difference between the $\mathrm{x}$-coordinate on the base map with the image, $\Delta \mathrm{y}$ is the difference between the $\mathrm{y}$-coordinates on the map of the base image, and $\mathrm{n}$ is the number of points.

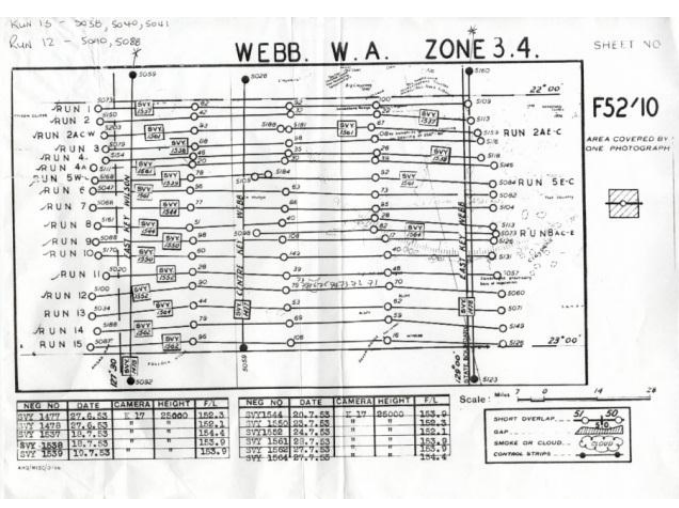

Figure 2. Original Webb W.A Zone 3.4 Flight Plan

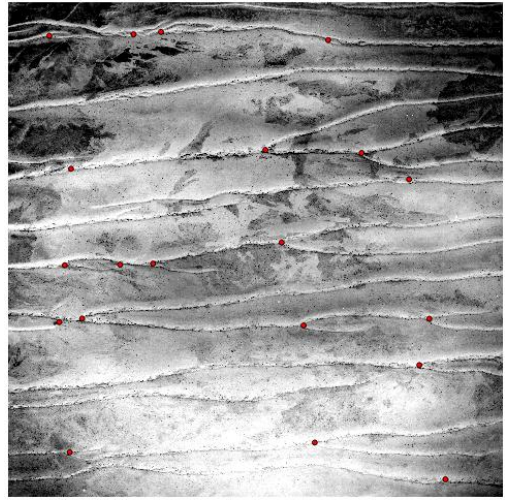

Figure 3. Ground Control Point Distribution

\section{RADIOMETRIC ENHANCEMENT AND IMAGE MOSAICING}

Histogram equalization, known as spatial feature manipulation in remote sensing, is one of the well-known enhancement techniques. In histogram equalization, the dynamic range and contrast of an image is modified by altering the image such that its intensity histogram has a desired shape, in order to eleminate the noise. This is achieved by using cumulative distribution function as the mapping function. (Gonzalez, 2002; Purwadhi, 2001). The modification of dinamic range and contrast of and images could be seen trough the histogram, whether it is the change of the peak, compression or stretched of digital numbers, and could be divided into spatial filtering, edge enhancement, and fourier analysis (Gonzalez, 2002; Purwadhi, 2001; and Sasi, 2013).

In the previous works, Contrast Limited Adaptive Histogram Equalization (CLAHE) have been successfully proven to be effective in biomedical image analysis, especially for detecting abnormalities in dense mammograms due to it's capability to leaving the luminance channel unaffected which results in an enhanced image output in color 
space (Pisano, 1998; Sasi, 2013). Assuming that the aerial images are having the same problems, the CLAHE techniques are implemented in this research.

Teoritically, the CLAHE will cut the histogram at some threshold and equalized the digital number under the treshhold value by distributing it across the histogram using a defined curve fitting distribution, where the contrast of an image is enhanced by applying CLAHE on small data regions called rather than the entire image. The resulting neighboring tiles then interpolated using bilinear interpolation. Using this technique, the homogeneous region contrast will be limited, to avoid any noise amplification (Pizer, et al., 1990; Garg, 2011; Srinivasan, 2006; Shome, 2011; Stark, 2000; Sasi, 2013). The concept of CLAHE in each data region/ tiles shown in figure below.

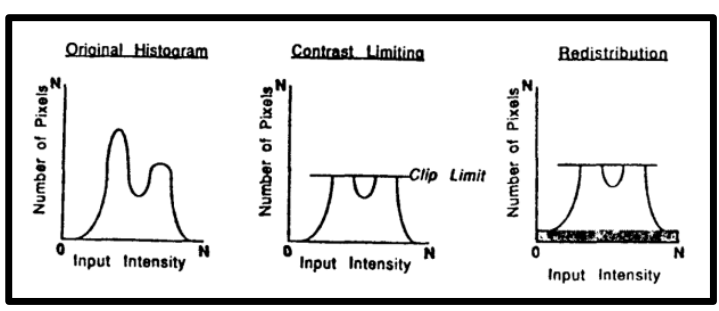

Figure 4. Concept of CLAHE (Pizer, et al., 1990)

One of the CLAHE distribution that normally used is Rayleigh distribution, which produces a bell-shaped histogram. Compared to another method, the bell-shaped histogram were widely used due to the flexibility of statictical assesement of the distribution parameters, such as mean, variation/ standard deviation, and maximum minimum value (Hitam, M.S, et al., 2013). The function in every tiles is given by

$$
\text { Rayleigh } g=g_{\min }+\left[2\left(\alpha^{2}\right) \ln \left(\frac{1}{1-P(f)}\right)\right]^{0.5}
$$

where gmin is a minimum pixel value, $\mathrm{P}$ ( $\mathrm{f}$ ) is a cumulative probability distribution and is a nonnegative real scalar $\alpha$ specifying a distribution parameter. The key parameters, block size and clip limit, are used to control image quality (Min et al., 2013). In their research, the clip limit value used is 0.01 and the $\alpha$ is specified to 0.4.

Using MATLAB, the CLAHE are registered as Adapthisteq function. According to MATLAB documentation manual (The MathWorks, Inc, 2012) this function also allows several change in parameters according to the user preferences. CLAHE method is designed to allow the observer to easily see, in a single image, all contrast of objects user-selectable preferences of parameters, resulting a different setting heuritically choosen by the observer (Pizer, 1987; Zimmerman, 1988; Sasi, 2013; Hitam, M.S, et al., 2013; Min, et al., 2013; Redweik, et al., 2008) This research will be based on parameters shown by (Hitam, M.S, et al., 2013) with only value change in the clip limit value, reduced to 0.008 due to the unnecessary use of higher contrast that damage the object detail of the burned regime, unburned regime, and sand dunes. As seen on the flight mission report, the schedule of data acquisition is different each row. This practice resulting also resulting a difference illumination, atmospheric condition, and CLAHE clip limit parameters in several images. (Min et al., 2013) proposed a novel method to determine the clip limit to improve the complexity of the image, shown by the image entropy number. Higher image entropy number will resulting higher clip limit value. Using the method shown in (Min et al., 2013), some image histogram were equalized using clip limit value of 0.006 an 0.007 .

Mosaicking is the process of combining multiple images into a single seamless composite image (Jensen, 2005). Having series of unstitched manually georeferenced and enhanced aerial image repository, the mosaicking process will be adapting the area Voronoi diagrams with overlap (AVDO) without any additional radiometric enhancement or color balancing method (Pan, et al., 2009). In this research, an automatic seamlines generation and manual seamline editing will be used to eliminate the effect of high lens distortion on the most outer part of the several images. The result is shown below.
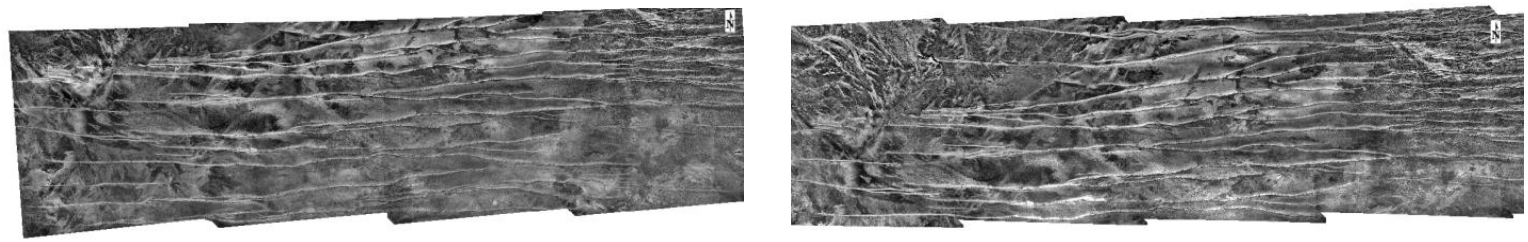

Figure 5. CLAHE and Seamless mosaic result on $1^{\text {st }}$ and $2^{\text {nd }}$ row of flight path 


\section{OBJECT BASED IMAGE ANALYSIS (OBIA)}

According to Katagis et al. [35], the selection of an appropriate procedure or technique in classification is depend on the aim of the study, data availability and ecosystem characteristics, whether in raster-based or object-based environment. The use of objects, instead of pixels, generally that can facilitate the usage of, spectral, contextual and spatial information, considering the shape and texture of objects, as well as topological features, especially in high resolution image due to the digital number variety inside the same objects [40,41; Laliberte, at al., 2006]. General steps used in OBIA are [1] Image Preprocessing; [2] Image Segmentation; [3] Sample collection; [4] Parameter and Treshold Definition; [5] Classification; [6] Accuracy Assesement (Wasil et al., 2012). However, the image preprocessing data is assumed finished after the mosaic process, producing balanced and contrast input .

The first and most important step in OBIA is the image segmentation. Segmentation algorithms are used to subdivide entire images at a pixel level, or specific image objects from other domains into smaller image objects (eCognition Handbook, 2011). Several types of image segmentation algorithms were developed for a variety of applications ranging from medical imaging to remote sensing image analysis, but, he effectiveness of the OBIA depends entirely on the quality of the segmentation result (Marpu, 2010). Determination of the most suitable segmentation in this research will be based on the result of comparison between two types of advance segmentation in eCognition 8.7, Contrast Filter Segmentation and Multiresolution Segmentation; trough accuracy assesement to identify burned area, unburned area, and sand dunes.

\section{SEGMENTATION}

Contrast filter segmentation is an advance segmentation algorithm that combine a chessboard segmentation is to convert this thematic layer into an image object level, then segmenting pixels inside the chessboard is classified and reshaped using multiscale contrast gradien treshold. Fig. 2.1 shows the general process of contrast filter segmentation. Based on eCognition manual book (2009), several parameters have to be defined to run the algorithm, the chessboard settings, shape criteria and classification defintion. Substantially, the main process are in the chessboard settings; the shape criteria used to merge the segmentation result and the classification definition is used to assign the segmentation result according to each layer of the multiscale chessboard used.

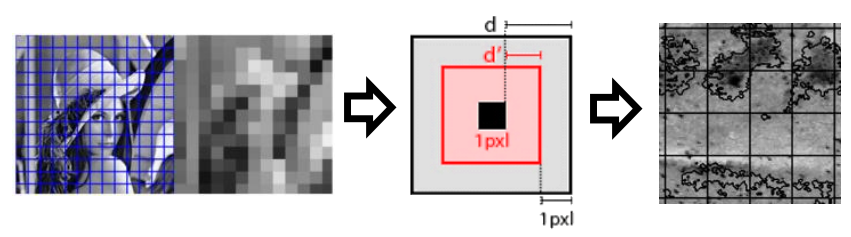

Figure 6. General idea of Contrast Filter Segmentation

In chessboard setting, the main parameters are chessboard size/ object size; multi scale contrast layer (layer 1-4, Several scales can be defined and analyzed at the same time. If at least one scale is tested positive, the pixels are classified as image objects); the contrast gradient; and the minimum and maximum digital number threshold. The preferable parameters setting of this segmentation is determined by combining many possibilities of chessboard size using all four multi scale contrast layer with 5 pixels distance on each layer with value of 10 in contrast gradient. This settings found that 25 pixels of chessboard size, 10, 15, 20, and 25 pixels of contrast layer, and without applying any minimum and maximum threshold value, resulting 135.000 numbers of objects. The objects with 1 standard deviation of spectral value or fewer are merged, resulting 118.000 objects to make the computing process faster.

The second segmentation algorithm is Multiresolution Segmentation. The procedure for the multi-scale image segmentation presented here can be described as a bottom-up region-based merging technique (Darwish, et al., 2003; Happ, et al., 2010) It starts with each pixel as separate object forming one image object or region. At each step a pair of image objects is merged into one larger object. The merging decision is based on local homogeneity criteria, known as fusion factor (f) or homogeneity difference (Hdiff). It expresses the increase of heterogeneity resulting from the union of two segments and describes the similarity of adjacent image objects until user threshold known as Scale Parameters (SP) are met. Therefore a higher SP will allow more merging and consequently bigger objects, and vice versa (Darwish, et al., 2003; Happ, et al., 2010).

The homogeneity/ heterogeinity criterion is a combination of color (spectral values) and shape properties (splits up in smoothness and compactness). Applying different SP and color/shape combinations, the user is able to create a hierarchical network of image objects. The preferable parameters setting of this segmentation is determined by combining many possibilities of scale parameters, shape, and compactness. It is found that two level segmentation 
combines the raster and object approach performs better in burning regime, unburned regime and sand dunes, using value as follows:

Table 1. Parameter of Multispectral

\begin{tabular}{|c|c|c|c|c|}
\hline Level & $\begin{array}{c}\text { Scale } \\
\text { Parameter }\end{array}$ & $\begin{array}{c}\text { Shape } \\
(\mathbf{1}-\text { Color })\end{array}$ & Compactness & Objects \\
\hline $\begin{array}{c}\text { Level 1 } \\
\text { (Raster) }\end{array}$ & 10 & 0.5 & 0.5 & 18,000 \\
\hline $\begin{array}{c}\text { Level 2 } \\
\text { (Object) }\end{array}$ & 50 & 0.5 & 0.5 & 11,000 \\
\hline
\end{tabular}

\section{CLASSIFICATION}

Among the available algorithms in eCognition, several algorithm are noted to be more widely known of its simplicity and effectiveness, such as Descision Tree (DT) and Nearest Neighbor (NN), in pixel-based and objectbased environment (Katagis, et al., 2014; Wasil, et al., 2012; Wikantika et al., 2004; and Laliberte, at al., 2006). The NN technique required less time in the field and for image analysis, had comparable accuracy to the DT approach, and would be appropriate for mapping similar areas (Laliberte, at al., 2006). Regarding the future application to the wider area and using the same data sets for longer time serial fire history collection, the NN method are used due to its capability for mapping similar area/ condition.

The classification of NN method was based on fuzzy logic, where each class contains can consist sets of fuzzy expressions based on parameters. The fuzzy sets are defined by membership functions that identify those values of a feature that are regarded as typical, less typical, or not typical of a class using Euclidean Distance equation rules using this equation:

$$
S D x y c=\sqrt{\sum_{i=1}^{n}(\mu c i-X x y i)^{2}}
$$

where SDxyc is the value different from the object to the average value of c class, $\mathrm{i}$ is the layer of parameter, $\mathrm{n}$ is channel number, $\mathrm{c}$ is class number, Xxyi is parameter value of designed classes, dan $\mu \mathrm{ci}$ is the parameters value of the object (Katagis, et al., 2014; Melesse, et al., 2002).

The smaller the difference is between sample objects and the object to be classified, the higher is the membership value. The greater degree of membership between the best and second best class assignment, the better the classification stability of an image object. Combination of spectral and textural information/ parameters could provide complementary information, especially the spectral information is not sufficient for identification of spectrally similar landscape features (Wang, 2015). According to that, the first parameter will be used is the mean of spectral information, or brightness mean; and the brightness standard deviation. In additional to that, including texture measures in the object-oriented classification, the accuracy of classification could be increased substantially (Hurni, 2013).

Haralick et al) proposed 14 original statistics to be applied to the co-occurrence matrix to measure the texture features of a spesific pixel relative to another, called the The Gray level co-occurrence matrix (GLCM). The widely used standard procedure for the automatic extraction of GLCM textures is based on a mono-spectral images, using considered known and effective textural parameters such as energy/ angular second moment; contrast, entropy, and inverse difference / homogeinity (Huang et al., 2014; Zhang et al., 2015; Wikantika et al., 2003). Energy is a measure of the local uniformity

$$
\sum_{i=1}^{N_{g}} \sum_{j=1}^{N_{g}}(P(i, j))^{2}
$$

Where $\mathrm{i}$ is the row number, $\mathrm{j}$ is the column number, $\mathrm{P} i ; \mathrm{j}$ is the normalized value in the cell $\mathrm{i} ; \mathrm{j}$, and $\mathrm{N}$ is the number of rows or columns; all the equation in this context is use the same description.

Entropy is inversely related to the energy, and it reflects the degree of disorder in an image. When the image is texturally uniform, the value will be very low.

$$
-\sum_{i=1}^{N_{g}} \sum_{j=1}^{N_{g}} P(i, j) \log (P(i, j))
$$


Contrast measures the degree of texture smoothness, or the difference between the highest and the lowest value of a sets of pixels, called local variation of images. It resulted lower value when the image has constant gray levels.

$$
\sum_{i=1}^{N_{g}} \sum_{j=1}^{N_{g}}(i-j)^{2} \cdot P_{i j}
$$

The inverse difference describes the local homogeneity, which is high when a limited range of gray levels is distributed over the local image. Homogeneity weights the values by the inverse of the contrast weight with weights, decreasing exponentially according to their distance to the diagonal. If the image is locally homogeneous, the value is high.

$$
\sum_{i=1}^{N_{g}} \sum_{j=1}^{N_{g}} \frac{1}{1+(i-j)^{2}} \cdot P i j
$$

The GLCM is a matrix whose elements correspond to the relative frequency of occurrence of pairs of gray level values of pixels separated by a certain distance in a given directions of analysis: Horizontal $\left(0^{\circ}\right.$ or $\left.180^{\circ}\right)$, Vertical $\left(90^{\circ}\right.$ or $\left.270^{\circ}\right)$, Right Diagonal $\left(45^{\circ}\right.$ or $\left.225^{\circ}\right)$, Left diagonal $\left(135^{\circ}\right.$ or $\left.315^{\circ}\right)$. This research will be using all the direction and calculate the mean value for the clustering purposes in classification. Stratified Random Sampling were used in this research to calculate the fuzzy sets and threshold for each classes. This sampling method applied by choosing a scattered but proportional sample spatially around the image, it did not concentrate on certain area in order to represent the members of each class and it's variance.

This research will be using the error matrix to compare the usefulness of each segmentation process. The error matrix is currently at the core of the accuracy assessment literature. It is a simple cross-tabulation of the mapped class label against that observed in the ground or reference data for a sample of cases at specified locations, and obvious foundation analysis to understand their relation for accuracy assessment (Campbell, 1996; Canters, 1997; Jansen 1996)

\section{RESULT, ANALYSIS, AND CONCLUSION}

Data processing steps involves the geometric correction, CLAHE application, and image mosaicking. Overall accuracy of coordinate transformation using 20 ICP root means square value shows under 0.8 pixels of error. Using Landsat 8 panchromatic image as the reference, we were not able to provide a higher level of accuracy due to it's spatial resolution that almost four times lower, compared the original data. Value of 0.8 is considered good enough for being able to show the attitude of the camera during the exposure. the larger side shows the direction to fly the plane, where the front side of the aircraft was higher than the tail side.

Using CLAHE method, utilizing varies of parameters to manually balanced the image histogram distribution, the images then stitched together seamlessly. Below is the result ot image mosaic from $1^{\text {st }}, 2^{\text {nd }}, 2^{\text {nd }} \mathrm{A}, 3^{\text {rd }}, 4^{\text {th }} \mathrm{WC}$, and $5^{\text {th }}$ flight path. The red box shows the sample area for the OBIA segmentation comparison. From the stitched images, there are some edges that were not perfectly seamlessly stitched, that maintained as low as possible until the segmentation algorithm did not recognize the difference due to the low spectral difference of the edges.

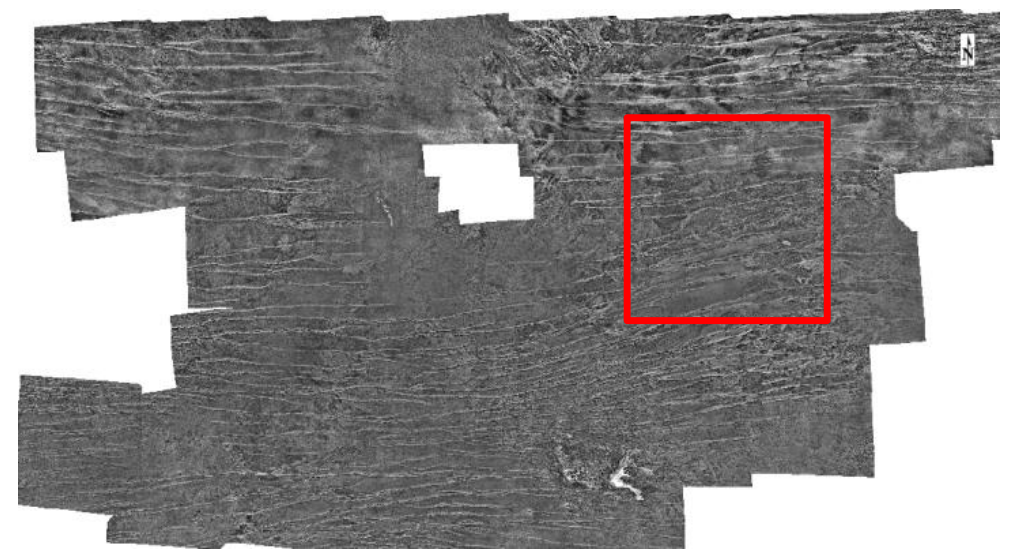

Figure 7. Mosaic result of $1^{\text {st }}$ to $5^{\text {th }}$ row of flight path 
The subsetted Region of Interest then segmented using preferable parametes after many attemps to determine the best segmentation to represent all the object on the image. below is the result of Multiresolution Segmentation and Contrast Filter Segmentation.

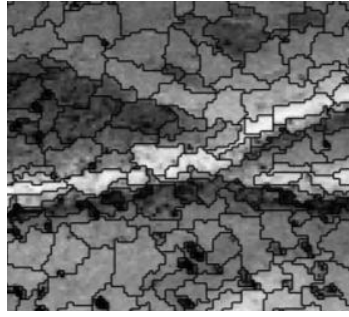

(a)

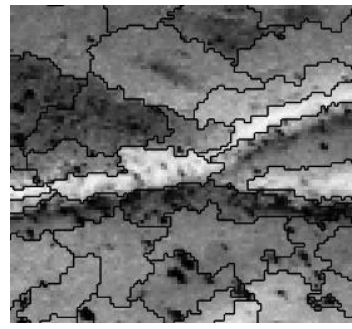

(b)

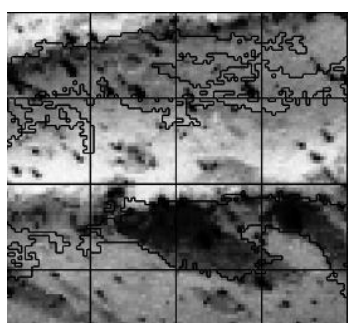

(c)

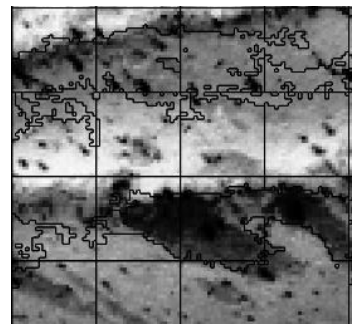

(d)

Figure 8. Comparison of Multiresolution Segmentation using 10 Parameter Scale (a) and 25 Parameter scale (b); Contrast Filter Segmentation using 25 Chessboard size (c) and 1 spectral standard deviation merge algorithm (d)

The smallest object could be identified in this imagery is considered as the burning regime. This research is aimed only to identify the burning regime then separate between the anthropogenic and natural fire regime manually according to the visual interpretation of experts. The segmentation result shows that the MS segmentation takes faster processing and comparable detail of burning regimes, while the CFS takes more time and segment, but better detail of objects. Using any parameters and classification method, more objects means more processing time needed. The goal in segmentation process is find the optimal objects but also having a preferable detail. The segmentation result then classified based on parameters shown below, using fuzzy nearest neighbor classification. The fuzzy sets are calculated based on the samples.

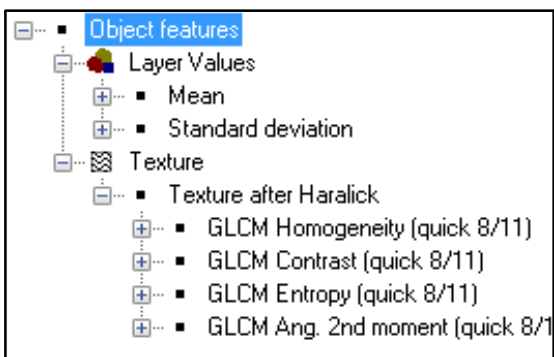

Figure 9. Classification Parameters

The result of classification shown below; Red is the burning regime, for the Multiresolution Segmentation and Contrast Filter Segmentation.

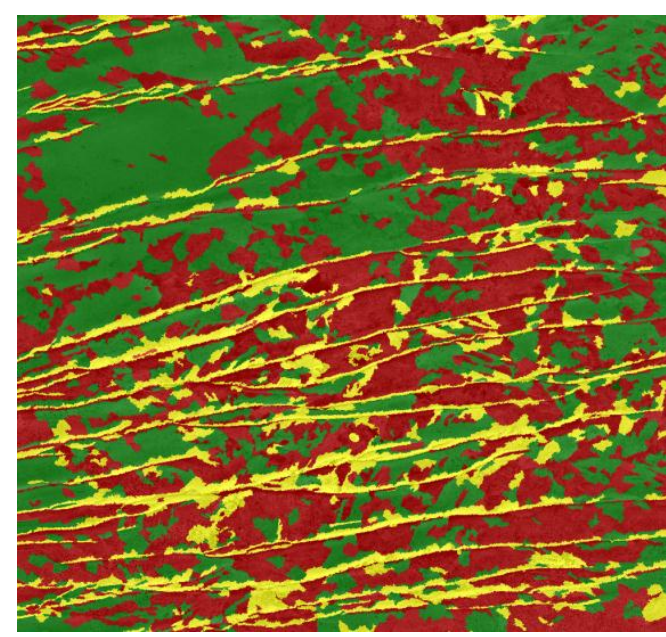

(a)

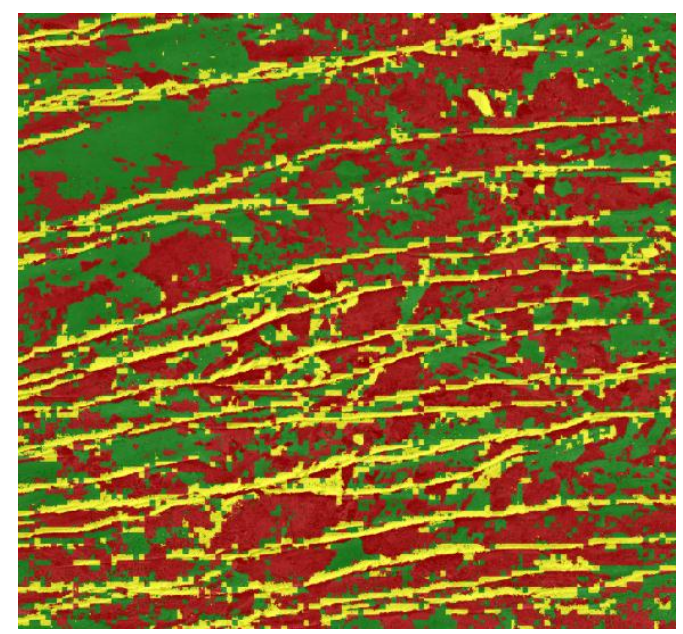

(c) 


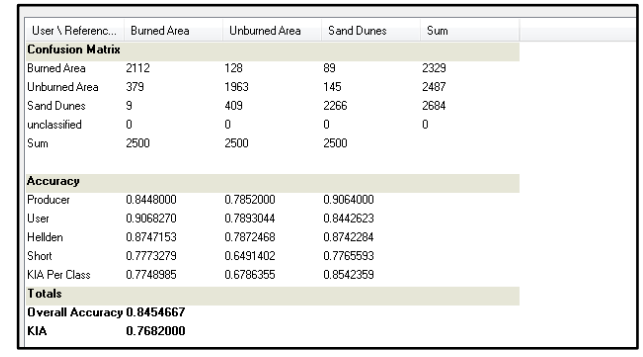

(b)

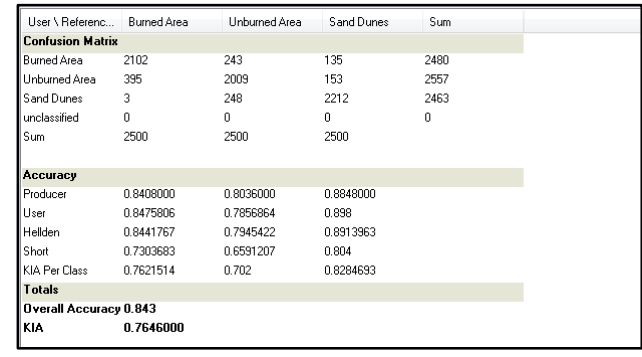

(d)

Figure 10. Classification result of Multiresolution Segmentation (a) and accuracy assesement result (b); and Classification result of Contrast Filter Segmentation (c) and accuracy assesement result (d)

From the result above, it is shown that Multiresolution is slightly better than Contrast Filter Segmentation according to 2500 spreaded random sample of 3 objects. Having the same reliable statistical accuracy, deeper qualitative analysis were conducted according to processing time, segmentation result, and object misclassification.

The processing time needed using the MS are faster almost by half the time needed using the CFS, using the same computer specification and data complexity. Beside of that, the segmentation using MS are more object-oriented compared to the the CFS, but the CFS segmentation result shows that the complexity of small burning regime (that is assumed as anthropogenic fire) is able to be detected, better than the MS.

The other consideration took account on the object misclassification shown by producer and user errors. The MS are more suitable for Burned area and Sand dunes classification, while the CFS gives the same result but lower accuracy. Based on those reason, the MS are stated better to identify the burning regime in trough this research.

\section{REFERENCES}

Bird, R.B., Bird, D.W., Smith, E.A., Kushnick, G.C. 2002. Risk and reciprocity in Meriam food sharing. Journal of Evolution and Human Behavior. 23 (2002) 297 - 321.

Bird, R.B., Bird, D.W., Parker, C.H..2005. Aboriginal Burning Regimes and Hunting Strategies in Australia's Western Desert. Journal of Human Ecology, Vol. 33, No. 4, August 2005. DOI: 10.1007/s10745-005-5155-0.

Bird, R.B., Bird, D.W., Codding, B.F., Parker, C.H., Jones, J.H.. 2008. The "Fire Stick Farming" Hypothesis: Australian Aboriginal Foraging Strategies, Biodiversity, And Anthropogenic Fire Mosaics. Proceedings of the National Academy of Sciences Vol. 105/39. 14796-14801, doi: 10.1073/pnas.0804757105.

Benz, U.C., Hofmann, P., Willhauck, G., Lingenfelder, I. and Heynen, M., 2004. Multi-resolution, object-oriented fuzzy analysis of remote senisng data for GIS-ready information. ISPRS Journal of Photogrammetry \& Remote Sensing, 58, pp. 239-258.

Davies, J., Holcombe, S. 2009. Desert knowledge: integrating knowledge and development in arid and semi-arid drylands. GeoJournal. Volume 74, Issue 5, October 2009

Debeir, O., Van den Steen, I., Latlanne, P., Van Ham, P., dan Wolf, E.. 2002. Textural and Contextual Land-Cover Classification Using Single and Multiple Classifier Systems, Photogrammetric Engineering \& Remote Sensing. 68:6, 597-605

Definiens Imaging. 2004. User Guide 4. eCognition

Gerard, F., Plummer, S., Wadsworth, R., Sanfeliu, A.F., Iliffe, L., Balzter, H., and Wyatt, B.. 2003. Forest Fire Scar Detection in the Boreal Forest with Multitemporal SPOT-Vegetation Data. IEEE Transactions on Geosci. and Remote Sensing, Vol. 41 No. 11.

Gonzalez, R., Wood, R.. 2009. Digital Image Processing, 3rd ed., Pearson Education.

Han, J., Lee, S., Chi, K., Ryu, K.. 2002. Comparison of Neuro-Fuzzy, Neural Network, and Maximum Likelihood Classifiers for Land Cover Classification using IKONOS Multispectral Data. Proceedings of the IEEE International Geoscience and Remote Sensing Symposium. Vol 6, pp. 3471-3473, Toronto, Canada.

Haralick, R.E., Shanmugam, K., Dinstein, I.. 1973. Textural Features for Image Classification, IEEE Transactions on Systems, Man and Cybernetics. Vol. SMC-3

Haralick R.E.. 1979. Statistical and Structural Approaches to Texture. Proceedings of the IEEE. Vol. 67, No. 5, pp. 786-804

Herold, M., Gardner, M. dan Roberts, D.. 2003. Spectral Resolution Requirements for Mapping Urban Areas. IEEE Transactions on Geoscience and Remote Sensing. Vol. 41: 1907-1919 
Huang, X., Liu, X., Zhang, L.. 2014. A Multichannel Gray Level Co-Occurrence Matrix for Multi/Hyperspectral Image Texture Representation. Remote Sens, 6, 8424-8445.

Min, B.S., Lim, D.K., Kim, S.J., Lee, J.H.. 2013. A Novel Method of Determining Parameters of CLAHE Based on Image Entropy. International Journal of Software Engineering and Its Applications Vol.7, No.5 (2013), pp.113120

Kohavi, R., and Provost, F. 1998. Editorial for the Special Issue on Applications of Machine Learning and the Knowledge Discovery Process. Applied Research in Machine Learning. Columbia University, New York, volume 30 .

Kressler, F.P.; Franzen, M.; Steinnocher, K. Segmentation Based Classification of Aerial Images and Its Potential to Support the Update of Existing Land Use Data Bases. In Proceedings of the ISPRS Hannover Workshop 2005: High-Resolution Earth Imaging for Geospatial Information, Hannover, Germany, 17-20 May 2005.

Laris P (2002) Burning the seasonal mosaic: Preventative burning strategies in the wooded savanna of Southern Mali. Human Ecology 30:155-186.

Marpu, P., Niemeyer, I., Nussbaum, S., Gloaguen, R.. 2008. Object-Based Image Analysis Spatial Concepts for Knowledge-Driven Remote Sensing Applications, ser. Lecture Notes in Geoinformation and Cartography. Berlin: Springer, pp. 169-185.

Pizer,S. M., Johnston, R. E., Ericksen, J.P., Yankaskas,B. C. Muller, K.E.. 1990. Contrast-Limited Adaptive Histogram Equalization: Speed and Effectiveness. IEEE Journal. THO31 1-1/90/0000/033.

Rao, C.N.; Sastry, S.S.; Mallika, K.; Tiong, H.S.; Mahalakshmi, K.B. 2013. Co-occurrence matrix and its statistical features as an approach for identification of phase transitions of mesogens. Int. J. Innov. Res. Sci. Eng. Technology, 2, 4531-4538.

Redweik, P., Roque, D., Marques, A., Matildes, R., Marques, F. 2008. Recovering Portugal Aerial Image Repository. Journal of Photogrammetry and Remote Sensing, XXXVIII.

Russell-Smith, J., Craig, R., Gill, A.M., Smith, R., William, J.. 2002. Australian Fire Regimes: Contemporary Patterns (April 1998 - March 2000) and Changes Since European Settlement. State of the Environment Second Technical Paper Series (Biodiversity). Department of the Environment and Heritage, 2002 ISBN 0642548013

Russell-Smith, J., Ryan, P. G., and Durieu, R. (1997b). A Landsat MSS-derived fire history of Kakadu national Park, monsoonal northern Australia, 1980-94: Seasonal extent, frequency and patchiness.Journal of Applied Ecology34: 748-766

Sari, N. M., dan Kushardono, D.. 2014. Klasifikasi Penutup Lahan Berbasis Objek Pada Data Foto UAV untuk Mendukung Penyediaan Informasi Penginderaan Jauh Skala Rinci. Jurnal Penginderaan Jauh, Vol. 11 No. 2, 114-127.

Shome, S.K., and Vadali, S.R.K..2011. Enhancement of Diabetic Retinopathy Imagery Using Contrast Limited Adaptive Histogram Equalization. International Journal of Computer Science and Information Technologies, Vol. 2, No. 6, pp. 2694-2699.

The American Society for Photogrammetry and Remote Sensing (ASPRS) (1990). ASPRS Accuracy Standards for Large-Scale Maps. ASPRS Professional Practicing Division, March, 1990.

The United States Geological Survey (USGS), 2014. LANDSAT 8 Satellite image http://landsat.usgs.gov/. Diakses pada tanggal 8 Maret 2014

Wasil, A.R.. 2012. Identifikasi dan Perhitungan Luas Sawah dengan Citra Satelit Resolusi Tinggi Menggunakan Metode Object Based Image Analysis. Bunga Rampai. Penerbit ITB.

Wells, 2013. The Australian desert - the outback of Australia. www. australia.gov.au

Wikantika, K., Uchida, S., dan Yamammoto, A. (2001) : An Evaluation of the Use of Integrated Spectral and Textural Features to Identify Agricultural Land Cover Types in Pangalengan, West Java, Indonesia, JARQ,38:2, 137-148.

Zuiderveld, K. Kardoulas, N.G., Bird, A.C., dan Lawan, A.I. (1996). Geometric Correction of SPOT and Landsat Imagery: A Comparison of Map and GPS-Derived Control Points. Photogrammetric Engineering \& Remote Sensing Journal, Vol. 62, No. 10, hal. 1173-1177. 